\title{
Immunotoxins: Targeted Toxin Delivery for Cancer Therapy
}

\author{
Xin Mei ${ }^{1,2}$ Junsheng Chen ${ }^{3,4}$ Jing Wang ${ }^{3,4}$ Jianwei Zhu ${ }^{1,2,3,4}$ \\ ${ }^{1}$ Jecho Laboratories, Inc. Maryland, United States \\ Address for correspondence Jianwei Zhu, PhD, MBA, Shanghai Jiao \\ 2 Jecho Biopharmaceuticals Co., Ltd., Tianjin, China \\ Tong University, 800 Dong Chuan Rd, Shanghai 200240, China \\ 3 Engineering Research Center of Cell and Therapeutic Antibody, \\ (e-mail: jianweiz@sjtu.edu.cn). \\ MOE, China \\ ${ }^{4}$ School of Pharmacy, Shanghai Jiao Tong University, Shanghai, China \\ Pharmaceut Fronts 2019;1:e33-e45.
}

\begin{abstract}
Keywords

- cancer

- immunotherapy

- immunotoxin

- protein toxin

- antibodies

- immunogenicity

- nonspecific toxicity

Immunotoxins are proteins that consist of a protein toxin conjugated to a specific targeting moiety. The targeting moiety is usually an antibody or ligand, such as monoclonal antibody, antibody fragment, a cytokine, or a growth factor. The toxins usually come from plant toxins, bacterial toxins, or human-origin cytotoxic elements. Nearly all toxins work by enzymatically inhibiting protein synthesis. After binding to antigens or receptors on target cell surfaces, immunotoxins are internalized and translocated to the cytosol where they can kill the cells. Immunotoxins have demonstrated high cytotoxicity to cancer cells and to date two immunotoxins have been approved by U.S. Food and Drug Administration on the markets for the treatment of hematological tumors: Lumoxiti and Ontak. Many other molecules are under development or clinical trials for different forms of cancer. Although immunotoxins exhibit great potency in xenograft model systems and early clinical trials, there are obstacles that limit successful treatments, including immunogenicity, nonspecific toxicity, and poor penetration. However, efforts are underway to address these problems. In this review, we summarize immunotoxins currently in clinical trials for either hematological tumors or solid tumors, outline the design of immunotoxins utilizing variety of components, and discuss the prominent examples of redesigned immunotoxins with reduced immunogenicity and nonspecific toxicity, as well as the strategies in manufacturing immunotoxins. With further improvements, it is anticipated that immunotoxins will play an increasing role in cancer therapy.
\end{abstract}

\section{Introduction}

Over a century ago, Paul Ehrlich proposed the "Magic bullet theory of targeted therapy." He postulated that if a compound could be made that selectively targeted a disease-causing organism, then a toxin for that organism (in patients) could be delivered along with the agent of selectivity. The hybridoma technology introduced by Kohler and Milstein in 1975 enabled the production of monoclonal antibodies (mAbs) in a large scale. ${ }^{1}$ Fundamental knowledge gained on cancer antigens or receptors, the structures and mechanisms of mAbs as well as the achievements in recombinant DNA techniques and devel- opments in modern protein engineering trigger people's interest in developing novel antibody-based cancer therapies, including new mAb constructs ${ }^{2,3}$ and antibody-cytotoxic agent conjugates, ${ }^{4}$ including immunotoxins. ${ }^{5,6}$

In the past 20 years, the development of cancer therapeutic drugs was mainly focused on the field of mAbs. Despite the significant efficacy of mAbs, cancer is still far away from being completely cured. Therefore, many innovative biotherapeutics, which were safer and more effective, were developed to treat tumors in laboratories and clinics. In recent years, bispecific antibodies, ${ }^{7,8}$ immunotoxins, ${ }^{5,6}$ oncolytic viruses, ${ }^{9}$ and antibody-drug conjugate (ADC) drugs ${ }^{4}$ have gradually received

October 3, 2019

accepted

November 7, 2019
DOI https://doi.org/

10.1055/s-0039-1700507. ISSN 2628-5088. (c) 2019 Georg Thieme Verlag KG Stuttgart · New York
License terms

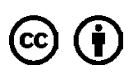


become research hotspots. In the immunotoxin field, there have been many valuable review articles summarizing research and clinical progresses available for references., Here, in this review article, the authors would like to provide updates on the progresses in the field with the focus on the immunotoxin molecules, clinical applications, and latest approaches using immunotoxins in cancer therapy.

Immunotoxins are proteins that consist of a protein toxin fused to a specific targeting moiety. Antibodies, antibody fragments, or growth factors are employed as targeting moieties. The toxin partners usually come from plants, bacteria, or human-origin cytotoxic elements, which act through enzymatically inhibiting protein synthesis. ${ }^{17}$ Many cases demonstrated the potential applications of immunotoxins in preclinical and clinical trials. ${ }^{7}$ To improve tumor penetration capacity, some immunotoxins are constructed by fusing a single-chain variable fragment (scFv) or single-domain antibody to toxins, which can lead to enhanced antitumor efficacy when they are delivered intrathecally or intratumorally. ${ }^{10-17}$ Compared with ADC molecules, most immunotoxins can be directly expressed as a fusion protein in host cells, which reduces the off-target effects caused by unstable junctions. ${ }^{4}$ The off-target side-effect, that toxins released from the delivery vehicles and bind to normal tissue before getting to target cells, led to unexpected cellular necrosis. ${ }^{4}$

\section{Immunoconjugates for Cancer Therapy}

There have been more than $70 \mathrm{mAbs}$ on the market and most of which are for cancer therapy. However, to enhance effectiveness of the targeted therapy, one design from logical thinking would be immunoconjugates with cytotoxic agents. The cytotoxic agents may be a chemotherapy drug, a protein toxin, or a radionuclide, thus creating ADCs, ${ }^{4}$ immunotoxins, ${ }^{5,6}$ or radioimmunoconjugates (RICs), ${ }^{18}$ respectively.

An immunoconjugate consists of three essential components: a target portion conjugated via a short spacer to a cytotoxic agent. The most important component of immunoconjugates is the targeting moiety, usually an antibody or cytokine. An ideal antibody should deliver and enhance accumulation of the conjugated payloads specifically to the targeted sites. Identification of an appropriate targeted antigen or receptor is the most important step in designing an immunoconjugate. The linker, linking of the payloads to the targeting moiety, and linkage strategy are another aspect that should be intensively considered. Critically, the linker should not affect the affinity with targets and be stable in bloodstream but labile once inside the targeted cells thus releasing the payloads in the active form. A series of regioselective linking techniques have been developed to fulfill this need. The third component of an immunoconjugate is the cytotoxic payloads. Payloads could be a chemotherapy drug, a protein toxin, or a radionuclide.

\section{Antibody-Drug Conjugates}

ADCs are molecules containing an mAb conjugated with a cytotoxic drug via a linker. ${ }^{4,19,20}$ Early ADCs were composed of whole murine antibodies conjugated to a traditional chemotherapeutic drug. These attempts were not successful due to the rapid clearance caused by the nonspecific toxicity to normal cells and tissues, immunogenicity, insufficient anticancer potency of the conjugated cytotoxic agents, and limited internalization, thus the amount of the effector accumulated in the targeted cells was not enough to trigger cell death. ${ }^{4,19,20}$ With experiences gained from these early explorations, several improvements were introduced in developing new ADCs. To date, there are three ADCs approved. The first approved ADC was gemtuzumab ozogamicin (Mylotarg), a humanized CD33-targeting IgG4 conjugated to calicheamicin via an acid-labile hydrazine linker. ${ }^{20,21}$ It was approved to treat CD33-positive acute myeloid leukemia (AML) in the year 2000 but withdrawn from the market in 2010. Brentuximab vedotin (Adcetris or SGN-35), an antiCD30 ADC conjugated to the auristatin derivative monomethyl auristatin E (MMAE) through the cleavable valinecitrulline dipeptide (vc) linker, was approved by U.S. Food and Drug Administration (FDA) in August 2011 for the treatment of Hodgkin lymphoma after the failure of autologous stem cell transplant and systematic anaplastic large cell lymphoma (ALCL) after failure of multiagent treatment. ${ }^{22}$ Trastuzumab emtansine (Kadcyla), ${ }^{23}$ a humanized HER-2targeted antibody conjugated to maytansinoid via a thioether linker, was the first ADC approved for treating solid tumors. The success of Adcetris and Kadcyla spurred the development of other ADCs targeting different numerous malignancies. To date, there are over 30 ADCs with different indications under development or clinical investigation. ${ }^{24}$

\section{Radioimmunoconjugates}

It was well established that a cancer cell was killed when a sufficient high dose of radiation was delivered. By combining the benefit of the specificity of antibodies and the high potency of radiation therapies, researchers developed RICs exhibiting high potency in treating cancers. ${ }^{18}$ RICs are mAbs labeled with therapeutic radionuclides which can deliver radiation precisely to the tumor cells or cells with heterogeneously expressed antigens. So far, two RICs targeting CD20 have been approved for treating hematological malignancies, ${ }^{90}$ Y-ibritumomab tiuxetan and ${ }^{131}$ I-tositumomab. Although RICs gained success in treating hematological malignancies, the responses in solid tumors were insufficient, which may be due to the poor radiosensitivity of these tumors as well as the inability to deliver sufficient doses to the targets. Optimizations on the antibodies' uptake could be made to enhance the efficacy of RICs. ${ }^{25}$ In the meantime, there are many other RICs in development, including at least 10 candidates for treating solid tumor. ${ }^{26}$ These advances give rise to a variety of opportunities in the management of various cancers, where the radiolabeled antibodies may be particularly useful in immunospecific phenotypic imaging, e. g., companion diagnostics. Concerning therapeutic applications, RICs have demonstrated their efficacy in the treatment of both hematological malignancies and solid tumors. ${ }^{18,25}$

\section{Immunotoxins}

Immunotoxins are chimeric proteins consisting of a targeting moiety and a cytotoxic protein, which were prepared by 
chemical conjugation or expressed as a fusion protein. To date, denileukin diftitox [Ontak] and anti-CD22 antibody with PE38 [Lumoxiti] are the two immunotoxins approved on markets. Ontak, approved in 1999, is a fusion protein consisting of an interleukin-2 (IL-2) receptor targeting a portion conjugated to a modified diphtheria toxin (DT), and was used in treating of CD-25 positive cutaneous $\mathrm{T}$ cell lymphoma (CTCL). ${ }^{27}$ Lumoxiti, approved in 2018, is a fusion protein consisting of disulfide bond stabilized Fv targeting CD22 fused with toxin PE38 to treat hairy cell leukemia (HCL) in clinics. ${ }^{12,28,29}$

All the immunoconjugates mentioned above are based on the concept of "magic bullet." By taking the advantage of the target specificity, mAbs, ADCs, immunotoxins, and RICs can selectively deliver cytotoxic agents to the targeted cells and cause the apoptosis of the target cells while minimizing nonspecific toxicity induced by cytotoxic agents.

\section{Mechanism of Cancer Therapy by Immunotoxins}

There are quite a few different designs of an immunotoxic molecule, which may have different mechanisms in target cell killing. The function of the targeting moiety is to bind to the corresponding antigen or receptor and trigger endocytosis. After receptor-mediated internalization, the toxin moiety is activated by proteolysis, then exerts cytotoxic activity. Generally cancer cell killing by immunotoxins can be summarized as the following three steps: first, binding to the target cells: the antigen- or receptor-binding domain of the immunotoxin binds to the corresponding antigen or receptor on the surface of the target cells. Second, entering into the target cells: the translocation domain of the immunotoxin promotes the toxin moiety entry into the target cells by endocytosis or transmembrane transport. ${ }^{30}$ Lastly, killing the target cells: the catalytic domain of the immunotoxin in the target cell could trigger cell death by inhibiting target cell protein synthesis or activating some important apoptotic proteins. ${ }^{31,32}$ The mechanisms of different toxins are illustrated by Wayne et al as shown in - Fig. 1. ${ }^{31}$

Human toxins are human cytolytic fusion proteins (hCFPs) that cause cell death through an apoptosis pathway ( - Fig. 2). ${ }^{33}$ Compared with toxins from bacteria and plants, hCFPs have lower immunogenicity and cytotoxicity, with higher tumor selectivity and infiltration ability. At present, most of the human toxins used in research are granzyme $B(\mathrm{GrB})$ and ribonucleases (RNases). GrB translocates across the lipid membrane together with perforin, ${ }^{34,35}$ then attacking its target substrate to activate the apoptosis pathway. ${ }^{34-37}$ Natural and engineered RNases may degrade tRNA in vivo to terminate protein synthesis that will lead cell death through apoptosis. ${ }^{38-41}$

\section{Immunotoxins in Clinical Trials}

Many immunotoxins were in clinical stages targeting on both hematological tumors and solid tumors. Two immunotoxic drugs were approved by FDA on global markets ( - Table $\mathbf{1}$ ). Different types of leukemia including CTCL, AML, chronic lymphocytic leukemia (CLL), HCL, non-Hodgkin lymphoma (NHL), etc. were treated by several immunotoxins in clinical stages I to III (- Table 1) targeting on CD3, CD22, CD25, CD30,

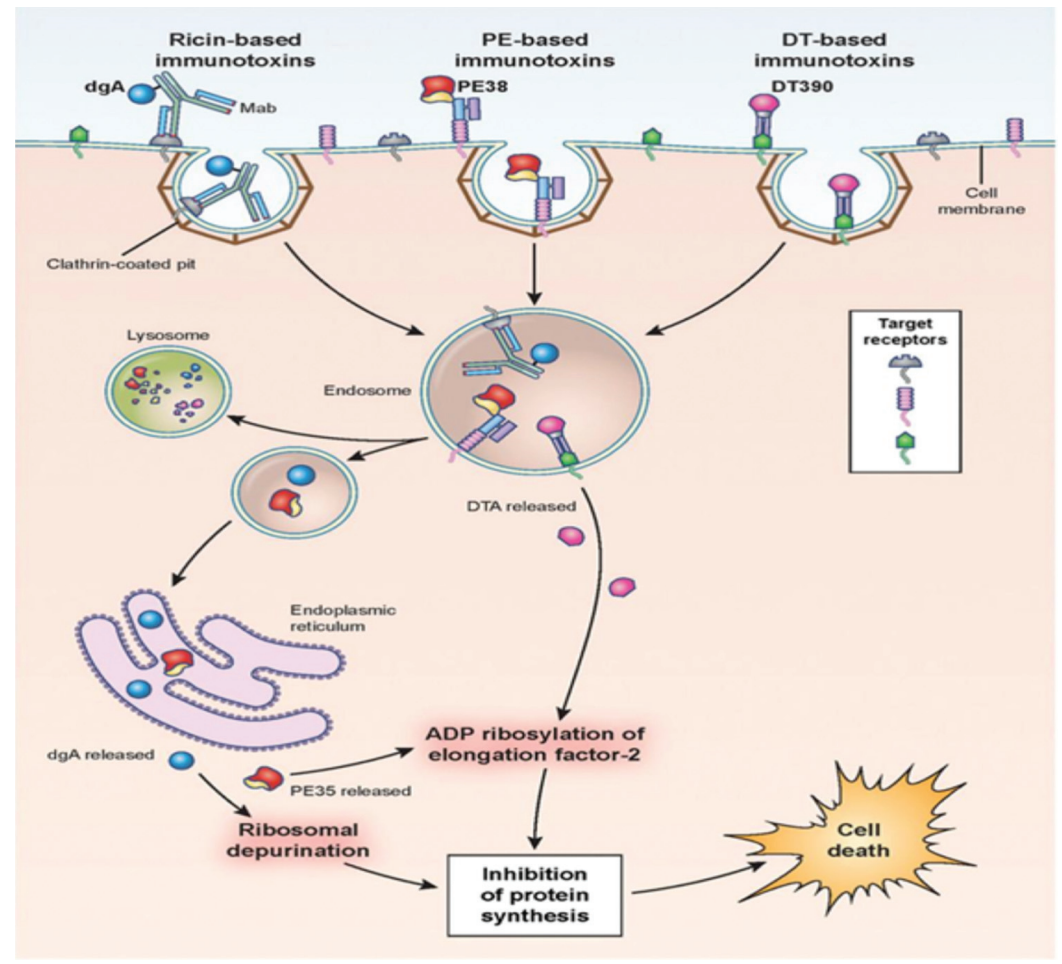

Fig. 1 Mechanisms of immunotoxins with three different kinds of protein toxin killing of cells. Ricin-, diphtheria-, and Pseudomonas-based immunotoxins are shown in the diagram. After binding the antigen, immunotoxins are internalized by clathrin-coated pits and reached the endosome. Pseudomonas and ricin traffic from the endoplasmic reticulum (ER) to the cytosol and then inhibit the protein synthesis. Diphtheria toxins are internalized and then the A chain of the toxin is transported to the cytosol to inactivate EF-2. Inhibition of protein synthesis finally caused the cell death. ${ }^{31}$ 


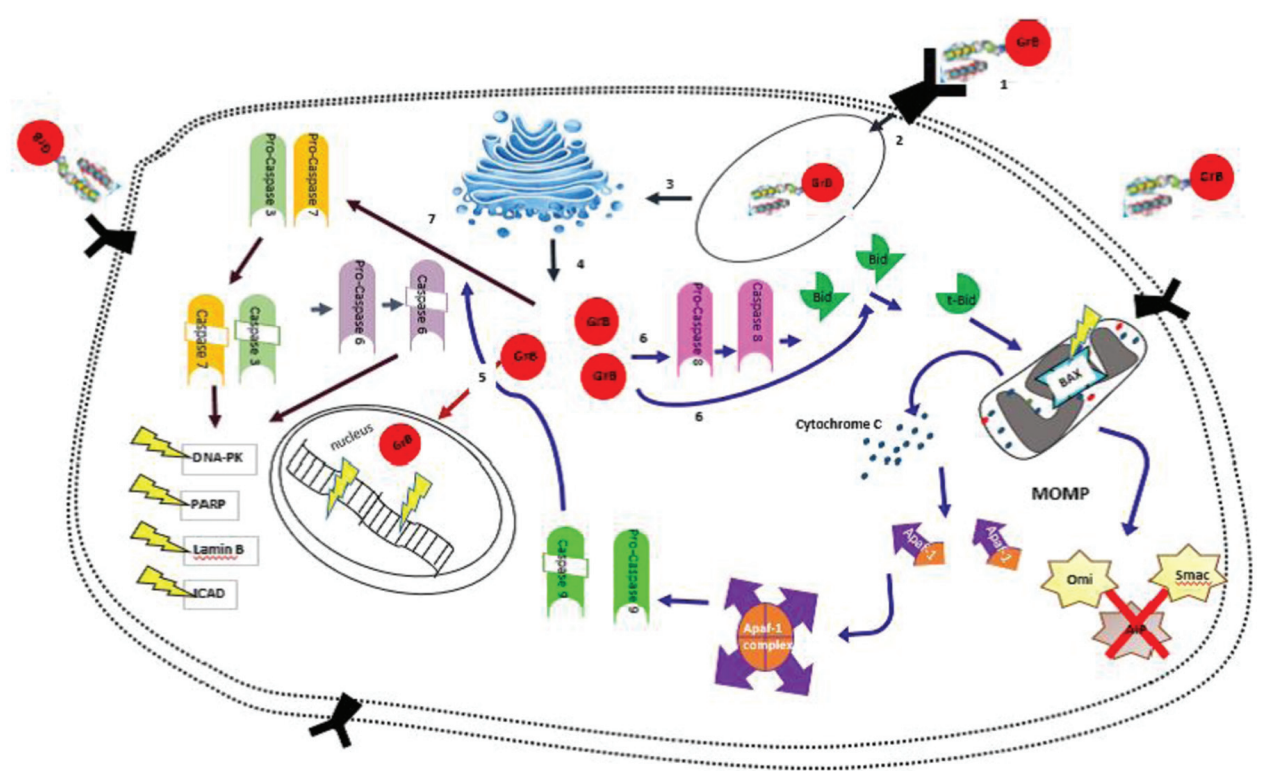

Fig. 2 Mechanism of granzyme B (GrB) targeted delivery to the tumor cell. (1) Binding of GrB to the cell membrane receptor; (2) internalization of GrB into the cell; (3) GrB escaped from endosome; (4) activated GrB reached the cytoplasm; (5) nuclear machinery underwent direct cleavage; (6) the caspase/mitochondrial independent pathway was initiated; (7) the caspase-dependent pathway was initiated. ${ }^{33}$

CD33, etc. on B-cells and others. In certain case, for instance, $\mathrm{HCL}$, it is rare disease and no effective medication before HA22 (Lumoxiti) used in clinic. ${ }^{28,29}$ After several years of clinical development, Lumoxiti was finally approved to global market in August 2018. ${ }^{29}$ Up to now, Pseudomonas exotoxin $\mathrm{A}(\mathrm{PE})$, ricin, $\mathrm{DT}$, and gelonin have been the commonly used toxins in research laboratories and clinical development.

Clinical development for solid tumors would be much more challenged, as it could be much more difficult than targeting hematologic tumors. Tumor tissues are packed tightly and the mass increases rapidly. The patients are less immunosuppressed and more likely to make neutralizing antibodies to the toxin. Many popular molecules for cancer research including mesothelin, epithelial cell adhesion molecule (EpCAM), EGFRvIII, ErbB2, transferrin receptor (TfR), and IL-13R were used as action targets for a variety of cancer diseases such as mesothelioma, lung, head, neck, bladder, breast cancers, glioblastoma, brain, and CNS tumors. Toxin partners used in these studies were similar to those developed in hematological tumors. Although there is no market product approved in this field, several treatment options of glioblastoma have entered late-phase clinical trials, $^{42,43}$ such as VB4-845, IL13-PE38QQR, and TfCRM107 (- Table 2). ${ }^{42-51}$

IL-13-PE38QQR (cintredekin besudotox) has entered phase III clinical trials; it has been developed as a specific tumor-targeting agent, which was administered by positivepressure convection-enhanced delivery directly to brain tissue at risk for residual infiltrating glioblastoma multiforme after tumor resection. ${ }^{43}$

VB4-845 (oportuzumab monatox) is a humanized scFv immunotoxin targeting EpCAM. It is conjugated with a

Table 1 Immunotoxins targeting on hematological tumors

\begin{tabular}{|c|c|c|c|c|c|}
\hline Immunotoxin & Targeting moiety & Toxic moiety & Target & Type of tumor & Clinical phase \\
\hline DAB389IL2 & IL2 & DAB389 & IL2R & CTCL, NHL, CLL, NSLC & Approved for $\mathrm{CTCL}^{27}$ \\
\hline $\mathrm{HA} 22$ & Anti-CD22 dsFv & PE38 & CD22 & ALL, HCL, NHL, CLL & Approved for $\mathrm{HCL}^{28,29}$ \\
\hline LMB-2 & Anti-CD25 scFv & PE38 & CD25 & CLL, CTCL leukemia & Phase $\|^{55,56,117}$ \\
\hline DT388 GMCSF & GMCSF & DAB388 & GM-CSFR & AML, CML & Phase $\mathrm{I}^{117}$ \\
\hline RFT5-dgA & Anti-CD25 mAb & $\mathrm{dgA}$ & CD25 & NHL, CTCL & Phase I, $\|^{55,56}$ \\
\hline UCHT1 & Anti-CD3 biFv & DT & CD3 & CTCL, T cell lymphoma & Phase I, II18 \\
\hline RFB4-dgA & Anti-CD22 Fab & $\mathrm{dgA}$ & CD22 & B-NHL & Phase $I^{119}$ \\
\hline $\mathrm{K}_{\mathrm{i}}-4 . \mathrm{dgA}$ & Anti-CD30 mAb & $\mathrm{dgA}$ & CD30 & $\mathrm{HD}, \mathrm{NHL}$ & Phase $I^{120}$ \\
\hline HuM195/rGel & Anti-CD33 MAb & Gelonin & CD33 & AML, CML & Phase $\mathrm{I}^{71}$ \\
\hline DT388-IL3 & Variant IL3 & DT388 & IL3R & AML, MDS & Phase I, II 117,121 \\
\hline
\end{tabular}

Abbreviations: AML, acute myeloid leukemia; CLL, chronic lymphocytic leukemia; CTCL, cutaneous T cell lymphoma; $\mathrm{HCL}$, hairy cell leukemia; NHL, non-Hodgkin lymphoma. 
Table 2 Immunotoxins targeting on solid tumors

\begin{tabular}{|l|l|l|l|l|}
\hline Immunotoxin & Toxic moiety & Target & Type of tumor & Clinical phase \\
\hline SS1P & PE38 & Mesothelin & Mesothelioma, head and neck cancer, lung cancer & Phase I, II ${ }^{44,49}$ \\
\hline VB4-845 & PE & EpCAM & Head and neck cancer, squamous cell and bladder cancer & Phase II, III $^{42}$ \\
\hline MR1-1 & PE & EGFRvIII & Malignant brain tumor & Phase I $^{45}$ \\
\hline TP38 & PE38 & EGFR & Brain and CNS tumor & Phase II $^{46}$ \\
\hline Erb38 & PE38 & ErbB2 & Breast carcinoma & Phase I $^{47}$ \\
\hline IL13-PE38QQR & PE38 & IL13R & Glioblastoma, brain tumors & Phase III $^{43}$ \\
\hline IL4-PE38KDEL & PE38KDEL & IL4R & Brain, CNS, kidney cancers & Phase I, II \\
\hline Tf-CRM107 & DT (CRM107) & TfR & Glioblastoma, brain tumors & Phase I, III ${ }^{49,51}$ \\
\hline DAB389-EGF & DT (DAB389) & EGFR & EGFR-expressing carcinoma & Phase I, II \\
\hline
\end{tabular}

Abbreviations: CNS, central nervous system; EGFR, epidermal growth factor receptor; TfR, transferrin receptor; DD, Ontak (Denileukin Diftitox), Ontak.

recombinant humanized anti-EpCAM antibody scFv and PE. ${ }^{42}$ Once it binds to EPCAM on the surface of cancer cells, it is internalized to the cytoplasm to induce apoptosis. Oportuzumab monatox was granted orphan drug status in 2005 and a fast track qualification in 2018 for the treatment of nonmuscle invasive bladder cancer (NMIBC). Currently, the phase III VISTA study (NCT02449239) is evaluating NMIBC patients who have received BCG prior to treatment with oportuzumab monatox; the primary endpoint is the patient's complete response rate.

Tf-CRM107 is a conjugate protein of DT with a point mutation (CRM107) linked by a thioester bond to human transferrin (Tf). ${ }^{51}$ This conjugate exhibits potent cytotoxicity in vitro against mammalian cells expressing TfR. Phase I clinical trial results demonstrated that Tf-CRM107, delivered via a high-flow convection method utilizing stereotactically placed catheters, produced tumor response in patients with malignant brain tumors refractory to conventional therapy without severe neurologic or systemic toxicity. In the phase II clinical trial, the Tf-CRM107 treatment results in complete and partial tumor response without severe toxicity in 35\% of the evaluable patients.

Mesothelin is a tumor antigen that is highly expressed in many human cancers, including malignant mesothelioma and pancreatic, ovarian, and lung adenocarcinomas. Several antibody-based therapeutic agents including bispecific antibody, CAR-T cells, ADCs, and immunotoxins directed at mesothelin are under clinical evaluation. These include antimesothelin immunotoxins (SS1P, RG7787/LMB-100), chimeric antimesothelin antibody (amatuximab), mesothelin-directed ADCs (anetumab ravtansine, DMOT4039A, BMS-986148), live attenuated Listeria Vaccine monocytogenes expressing mesothelin (CRS-207, JNJ64041757), and so on. Two antimesothelin agents are currently in multicenter clinical registration trials for malignant mesothelioma: amatuximab in the first-line setting and anetumab ravtansine as second-line therapy. Phase II randomized clinical trials of CRS-207 as a boosting agent and in combination with immune checkpoint inhibition for pancreatic cancer are nearing completion. These ongoing studies will define the utility of mesothelin immunotherapy for treating cancer. ${ }^{49}$
Updated information on immunotoxins in clinical trials has been summarized by a number outstanding review articles recently. $6,13,14,52,53$

\section{Immunotoxin Classification}

Immunotoxins are proteins consisting of a targeting moiety which could selectively bind to a target cell and a killing moiety which could kill the targeted cell after internalization. The targeting moiety could be an antibody, antibody fragment, cytokine, or growth factor, while the most potent toxins are different types of enzymatic inhibitors of protein synthesis. A toxin moiety can be derived from bacteria, fungi, plants, or human cells. Therefore, immunotoxins may be classified according to targeting moieties and toxins.

\section{Immunotoxin Target and Targeting Moieties}

For cancer therapeutics, the goal of antibody-mediated killing is to eliminate the malignant cells. The choice of antibody will depend on the disease target based on results from basic researches. In general, specific antigens or receptors expressed on malignant cells rather than normal vital tissues are appropriate targets. These antigens and receptors should be internalized after antibody binding, ensuring that the toxin or drug is transported to the cell interior and then separates from the antibody and kills the cell. It is important to note that targeting antigens are not well validated, which is the risk in target selection. The risk is mitigated if the clinical results of targeting an antigen with an mAb are available. The targeting moiety of immunotoxins can be either an antibody (such as mAb, scFv, and single-domain antibody) or a ligand (such as cytokine, growth factor, and hormone peptide) that binds selectively to an antigen or a receptor expressed on the surface of the target cells.

\section{Cytokine Receptor as a Target and Ligand as a Targeting Moiety}

The IL-2R complex, which consists of three subunits $-\alpha$ (CD25), $\beta$ (CD122), and $\gamma$ (CD132)-is expressed on T lymphocytes and natural killer (NK) cells. ${ }^{54}$ Ontak is a fusion 
protein composed of IL-2 fused to the first 388 amino acids of DT. It has IL-2 instead of an Fv; it targets and kills cells in the same manner as an immunotoxin. Ontak binds tightly to the IL-2 but less to the $\alpha$ subunit. (Ontak (Denileukin Diftitox)) was approved for the treatment of CTCL in adults, and its activity has been reported in other hematologic malignancies, including IL-2R-expressing leukemia. ${ }^{54}$ The $\alpha$ subunit is mostly overexpressed in $\mathrm{T}$ cell malignancies, since newer immunotoxin attempts to bind this lower-affinity IL-2 receptor $\alpha$ subunit (CD25). ${ }^{55,56}$ LMB2 (anti-Tac [Fv]-PE38) is a fusion protein in which the Fv portion of an antibody to CD25, the $\alpha$ chain of the IL-2 receptor, is fused to PE38.

It has been proved that gliomas overexpress IL receptors. Cytokines IL-4 and IL-13 were used to target gliomas since they are overexpressed in tumor cells. IL4-PE toxin was also reported to show antitumor activity in vivo and regression of human glioblastoma tumors, thus leading to the ongoing phase I/II clinical trials. ${ }^{57}$ Tumor necrosis factor (TNF)-based immunotoxins were developed with antimelanoma antibody (scFvMEL), which showed cytotoxicity in nude mice. ${ }^{58}$

\section{Growth Factor Receptors as Targets}

Growth factor receptors are generally overexpressed in solid tumors, which make them as effective therapeutic targets. ErbB has higher expression levels in many tumors; ErbB2/ Her2 was targeted by ScFv (FRP5)-ETA for solid tumors. ${ }^{58}$ It consists of an N-terminal ScFv, genetically linked to truncated PE. Epidermal growth factor receptor (EGFR) is another growth factor being used widely for solid tumors. Anti-ScFv EGFRvIII-PE38 in an athymic rat model of neoplastic meningitis was reported to increase median survival. TP-38 is a recombinant chimeric-targeted toxin composed of the EGFR binding ligand TGF- $\alpha$ and PE-38. ${ }^{59,60}$

\section{Tumor-Associated Antigens as Targets}

The tumor-associated surface antigen EpCAM has been used to target solid tumors and has shown regression of large tumor xenografts derived from lung, colon, or squamous cell carcinomas using ScFv against EpCAM with PE. VB4-845 (or oportuzumab monatox, Proxinium) is a recombinant fusion protein that combines the specificity of an anti-EpCAM ScFv with the toxicity of PE $40 .{ }^{61-63}$ Mesothelin, expressed on mesotheliomas, ovarian, pancreatic, and lung cancers, has been targeted with PE toxin and was found to have a synergistic effect with chemotherapeutic agents in a mice model. ${ }^{44,49,64}$ One of the more interesting ITs is SS1P or antimesothelin (Fv)-PE38. ${ }^{44,49}$

CD3 is widely expressed in T cell malignancies. An anti-CD3 recombinant immunotoxin (RIT), AdmDT390-bisFv (UCHT1), was constructed from a divalent molecule consisting of two single-chain antibody fragments reactive with the extracellular domain of CD3. ${ }^{65}$ The combination of HD37-dgA and RFB4$\operatorname{dgA}$ (Combotox) has been studied in adults and children with B-lineage hematologic malignancies. In addition to this, a bivalent recombinant diphtheria-based immunotoxin has been developed in which one Fv targets CD19 and the other targets CD22 (DT2219ARL). This agent has shown activity in preclinical models and is in phase 1 testing in adolescents and adults with B-lineage hematologic malignancies including acute lymphoblastic leukemia (ALL). ${ }^{65-67}$

CD22 is a lineage-restricted differentiation antigen expressed on B cells and most B cell malignancies. Because it is rapidly internalized after binding, it is an attractive target for immunotoxins and ADCs. HA22 and variants are named in a patent, which claims a method for treating ALL in pediatric patients. ${ }^{68}$ In addition to $\mathrm{CD} 22$, the receptor CD25 has also been targeted to treat various leukemias and lymphomas. ${ }^{55,56}$ Clinical trials of IMTOX25, using immunotoxin of fusion dgA to anti-CD25 on CD25 positive refractory cutaneous $\mathrm{T}$ cell NHL and $\mathrm{T}$ cell leukemia or lymphoma were completed. ${ }^{56} \mathrm{CD} 30$ is expressed on several types of hematologic tumors, particularly in HL and ALCL. The antiCD30 mAb cAC10 was conjugated to MMAE through a valinecitrulline peptide linker to make SGN-35 or brentuximab vedotin. ${ }^{69,70} \mathrm{CD} 33$ is expressed on the surface of early multilineage hematopoietic progenitors, myelomonocytic precursors, cells of the monocyte/macrophage system, some lymphoid cells, 80 to $90 \%$ of cases of AML, and some cases of B cell precursor and T cell ALL. An anti-CD33 immunotoxin consisting of humanized mAb M195 conjugated to recombinant gelonin (HUM-195/rGEL) was tested in a phase I study in adults with myeloid leukemias. ${ }^{71,72}$

\section{Antibody as a Targeting Moiety}

Antibodies including ScFv, single-domain antibody, fulllength murine, and humanized antibodies can be used as targeting moieties. In the early stage, the targeting moieties of immunotoxins were mainly murine mAbs, which had limitations in clinical application due to their large molecular weight (MW) and high immunogenicity. So, smaller size targeting moieties such as ScFv, single-domain antibody, and humanized antibody were developed to reduce immunogenicity. The MW of the complete murine $\mathrm{mAb}$ is generally approximately $150 \mathrm{kDa}$, which may be difficult to diffuse and penetrate into the solid tumor cells due to their large MW. So these immunotoxins were often used for hematological tumors. Immunotoxins composed of such full-size mAbs not only have high immunogenicity, but also are difficult to express in host cells, due to their cytotoxicity. Despite all these, many different types of immunotoxins were still widely developed, as they also have several important advantages, such as a long half-life, strong antigen affinity, and low preparation costs. ${ }^{11}$

To overcome the shortcomings of the complete murine $\mathrm{mAb}$, researchers used genetic engineering technology to develop ScFv as the targeting moiety, which has smaller MW, and better permeability and stability. The ScFv has a MW of approximately $25 \mathrm{kDa}$, which is a combination of a lightchain variable fragment (VL) and a heavy-chain variable fragment (VH) via a flexible linker peptide, and the ScFv retains the specificity and affinity like the complete $\mathrm{mAb}$. The ScFv immunotoxins have shown good results in many studies in hematological and solid tumors.

On the basis of ScFv, to further reduce the MW of the targeting moiety of immunotoxins to benefit for fusion expression, researchers designed the single-domain 
antibody which only contains the VH. Its MW is about half of that of ScFv's, but it retains most of the antigen-binding ability as ScFv. ${ }^{73}$ However, with the decrease of the MW, the half-lives of the immunotoxins composed of ScFv or singledomain antibody were shortened and they were quickly eliminated from the body. ${ }^{73}$

The reason for using humanized antibody as the targeting moiety is to reduce the immune rejection induced by exogenous antibody. ${ }^{40}$ Compared with the murine antibody, humanized antibody reduces immunogenicity and retains the advantages of high affinity and long half-life. However, there still exist the disadvantages of large MW and low permeability. Humanized antibody has been also used as a targeting partner in ADC. As an example, Pfizer's Mylotarg (gemtuzumab ozogamicin), a conjugate of an anti-CD33 mAb with calicheamicin, was approved for AML in 2000 and reapproved in 2017. Although it is an ADC drug, it is very similar to humanized immunotoxin. It was prepared by a chemical coupling method and using humanized antibody as the targeting moiety. ${ }^{74}$

\section{Immunotoxins with Different Toxins}

Protein toxins exhibit high potency when compared with small molecular cell killing agents. It has been shown that one single molecule in the cytosol is sufficient to kill a cell, ${ }^{75}$ thus an extremely low concentration was needed. Among the vast protein toxins, three toxins were intensively studied and commonly used in developing immunotoxins: the bacterial toxins PE and DT, and the plant toxin ricin.

\section{Bacterial Toxins}

DT and PE are the most widely studied two bacterial toxins. ${ }^{76,77}$ Both PE and DT enzymatically ADP-ribosylate elongation factor-2 (EF-2) in the cytosol. ${ }^{76,77}$ They each catalyze the ADP-ribosylation of histidine-699 of EF-2, which is posttranslationally modified to a diphthamide residue 35 . Despite their similar action, PE and DT have quite different amino acid sequences. In fact, PE's enzymatic domain is near the carboxyl terminus, while DT's is near the amino terminus. Conversely, PE's binding domain is near its amino terminus, and DT's is near its carboxyl terminus. To reduce the nonspecific toxicity, the binding domain of the toxins was usually deleted to prevent their binding to normal cells. Based on the structural and functional studies, the most common truncated form of PE is PE38, which contains the amino acids 253-364 and 381-613, and the derived form PE38KDEL, in which the last four amino acid residues REDL at the $C$ terminal were replaced by KDEL to enhance the translocation to cytosol. For DT, the most commonly used truncated form is DT388 or DAB389, containing the first 388389 amino acids of DT. ${ }^{15,78,79}$

\section{Pseudomonas Exotoxin A}

$\mathrm{PE}$, a 613-amino acid peptide, is one of the virulence factors derived from Pseudomonas aeruginosa and could be structurally and functionally separated into three major domains. ${ }^{80-82}$ Domain Ia is composed of residue 1-252 and responsible for cell recognition and binding, while domain II, residue 253-
364, is involved in the translocation of the toxin into the cytosol. Domain III (amino acids 405-613), which is located at the $\mathrm{C}$ terminus of $\mathrm{PE}$, halts the protein synthesis by inactivating the eukaryotic translation EF-2 by catalytical ADPribosylation. ${ }^{79}$ The intoxication procedure was elucidated to contain the following steps: the toxin was first processed by carboxypeptidases in plasma to remove the C-terminus residue Lys613 leaving an REDL terminus, ${ }^{82}$ then domain Ia mediated the binding of the processed toxin to the receptor present on the target cell surface and the sequential internalization into the cell via an endosomal pathway; once internalized into the target cell, the toxin undergoes a transient unfolding and a subsequent proteolytic cleavage by furin at domain II $^{82}$ and a reduction of a key disulfide bond, then the Cterminal fragment of the toxin was transported to the endoplasmic reticulum (ER) via the binding of the 609-612 REDL terminus to the KDEL receptor, then domain II mediated the translocation of the toxin to the cytosol, and catalyzed the ADP-ribosylation of the residue in EF-2 and eventually caused the cell apoptosis in the cytosol. ${ }^{11,78}$

\section{Diphtheria Toxin}

DT is derived from the pathogen Corynebacterium diphtheriae, which is a single-chain protein containing 535 amino acids. Like PE, DT is composed of three domains, the enzymatic A domain (amino acids 1-193), the binding B domain (amino acids 482-535), and a translocation domain which is located between the A and B domains. ${ }^{81}$ DT shares a similar mechanism with PE, which is catalyzing the ADP-ribosylation of the EF-2 and causing the blockage in protein synthesis. More specifically, DT is cleaved outside the cell into two domains at the furin cleavage site, and forms a di-chain protein which is linked by a single disulfide bond. After binding to the target cell and internalized into the endosome, DT undergoes a transient unfolding at a low pH and a key disulfide bond was reduced. Then the active domain of DT is translocated to cytosol through a channel formed by the $\mathrm{T}$ domain and ADP-ribosylates the EF-2 and eventually halts the protein synthesis. ${ }^{83}$

\section{Plant Toxins}

Plant toxins can be classified into holotoxins and hemitoxins. Holotoxins (also referred to as class II ribosome-inactivating proteins [RIPs]) include ricin, abrin, mistletoe lectin, and modeccin. Hemitoxins, or class I RIPs, include pokeweed antiviral protein (PAP), saporin, bryodin 1 , bouganin, and gelonin. ${ }^{84}$ Holotoxins contain both binding and catalytic domains, whereas hemitoxins contain only the catalytic domain. Both of holotoxins and hemitoxins exert their toxic effects by inactivating the cell's ribosomes, thus they can work only when their enzymatically active domains enter the cytosol.

\section{Ricin}

Ricin as a representative of holotoxins is extracted from the seeds of castor. Natural ricin is a 64-kDa protein that consists of two domains. Domain A can permanently inactivate the ribosome of eukaryotic cells, and domain B can bind to glycoproteins and glycolipids on the cell surface. Ricin can 
enter the target cells by endocytosis, then the two domains of ricin are reduced in endosomal vesicles; the domain $A$ is transferred to the cytoplasm, which inactivates the ribosome by removing the base of G4323 in 28S rRNA of the ribosome, permanently inhibits cellular protein synthesis, and leads to cell death. ${ }^{85}$ The deglycosylated A-chain of ricin $(\operatorname{dg} \mathrm{A})$ was also used to construct immunotoxins with a slower clearance rate. Since it is not easy to express functional ricin in Escherichia coli, ricin-based immunotoxins were constructed by chemically conjugating the ricin or $\operatorname{dgA}$ prepared by reduction to a targeting portion. ${ }^{85}$

\section{Gelonin}

Gelonin is another plant-derived single-chain RIP (corresponding to the recombinant ricin toxin A [RTA] chain) exhibiting sound cytotoxicity and is applicable in gene manipulation and thus widely used in RIT construction. ${ }^{32}$ As a representative of hemitoxins, gelonin is often studied as the toxin moiety of immunotoxins. Gelonin is a single-chain soluble glycoprotein toxin with a MW of approximately $30 \mathrm{kDa}$ extracted from the seeds of the Himalayan plant Gelonium multiflorum. Many studies have shown that gelonin can prevent the association of EF-2 with the 60s ribosomal subunit by removing the base of A4324 in 28s rRNA. ${ }^{32}$

\section{Human Toxins}

Human toxins are hCFPs that also can trigger apoptosis and cause cell death. Compared with heterologous toxins, hCFPs have lower immunogenicity and cytotoxicity, while having higher tumor selectivity and infiltration ability. At present, most of the human toxins used in research are $\mathrm{GrB}^{33-37}$ and RNases. $^{38-40}$

\section{Granzyme B}

$\mathrm{GrB}$ is a serine protease found in cytoplasmic granules of NK cells and cytotoxic T cells. ${ }^{86}$ Due to cytotoxicity with $\mathrm{GrB}$, it was usually expressed as an inactive zymogen form, and the activity was recovered by lysosomal dipeptide protease to remove two propeptide amino acids, it is expressed as an inactive zymogen form, and can recover activity by lysosomal dipeptide protease to remove two propeptide amino acids. GrB can enter the cytoplasm of target cells through the pores in the cell membrane, and cause apoptosis by cutting various structural and functional proteins containing Aps-X, Glu-X sites, etc., such as a variety of caspases, BH3 proapoptotic protein. $^{33,34}$ In addition, GrB is the main effector molecule of the granzyme family. It activates the caspase cascade in target cells, which can rapidly cause DNA fragmentation and lead to cell apoptosis. It can also directly migrate to the nucleus, cutting nuclear proteins to promote nuclear apoptosis. ${ }^{35}$

\section{RNase}

RNase is capable of hydrolyzing phosphodiester bonds in mRNA, rRNA, or tRNA. ${ }^{39,40}$ RNases play a wide-ranging role in cell processes and correspond to different targets at different sites, even to stop the cell process for the survival of the body. ${ }^{39,40}$ RNases are nontoxic and can promote apoptosis by hydrolyzing RNA in the cytosol. As a toxin moiety of the immunotoxin, RNases have better biosafety and only exert cytotoxicity after entering the cell, inhibiting tumor growth by terminating the cell cycle. RNases can be fused to a targeting antibody or ligand to form an immunotoxin that selectively kills tumor cells, showing significant anticancer effects through specific tumor-cell surface antigens. ${ }^{39,40}$

The three major types of toxins discussed above, in which bacterial and plant toxins are highly immunogenic in clinical treatment, and the human toxins avoid this problem. As foreign proteins, nonspecific bacterial and plant toxins may induce the neutralizing antibodies when administrated. This results in a short half-life and thus high doses or more rounds are needed. Although many works have been done to mitigate the immunogenicity of these foreign proteins, fully humanorigin cytotoxic proteins stand another chance to construct immunotoxins with reduced or eliminated immunogenicity.

\section{Immunogenicity, Nonspecific Toxicity, and Other Side Effects}

RITs are genetically engineered proteins being developed to treat cancer. In the development of immunotoxins, immunogenicity and nonspecific toxicity are the major obstacles. The plant- or bacterial-derived toxins are foreign proteins that may induce neutralizing antibody formation in patients, thus causing rapid removal of the immunotoxin from the bloodstream, resulting in a decrease in therapeutic effect. The clinical success of RITs in patients with a normal immune system is limited by their immunogenicity. With a balancing act between immunogenicity and therapeutic potency, one approach is to prevent the activation of B cells by mapping and elimination of B cell epitopes. Another approach is to prevent helper $\mathrm{T}$ cell activation by interfering with major histocompatibility complex II presentation or T cell recognition. Immunizing mice with RITs that were deimmunized by elimination of the murine B cell or T cell epitopes showed that both approaches were effective. ${ }^{56,87}$ Nanoparticles containing synthetic vaccine particle encapsulating antigens was able to induce immune tolerance and prevent antidrug antibody formation. This treatment restores RIT antitumor activity that is otherwise neutralized because of immunogenicity. When treating patients with hematological malignancies, the immune system is suppressed by either the disease or chemotherapy. However, with solid tumors, the immune systems is intact, and the immunotoxins are neutralized after one cycle thus preventing effective retreatments. ${ }^{56,87}$

Several approaches have been attempted to overcome the problem of immunogenicity without compromising toxin efficacy. ${ }^{88-91}$ Chemically modifying the protein with high MW polyethylene glycol is a common approach to reduce or eliminate immunogenicity. ${ }^{30}$ Researchers tried to modify various immunotoxins with PEG and found PEGylation of toxin may result in a modest reduction in immunogenicity with an unaffected cytotoxicity. ${ }^{88}$

Intensive research studies have also been done to improve the PE moiety to produce smaller and less immunogenic PE molecules. HA22 was taken as the parental molecule. By locating the epitope groups and mutating the key amino 
acids in the epitope groups in $\mathrm{PE},{ }^{88}$ a mutant immunotoxin HA22-8X was constructed. Domain II contains a lot of proteolytic sites. By deleting domain II except for the furin cleavage site, a smaller toxin HA22-LR (lysosome resistant) was constructed. HA22-LR exhibited more cytotoxic activity to CLL samples than HA22, which may due to the resistance to the proteolytic process while trafficking to the ER. ${ }^{88} \mathrm{New}$ immunotoxins HA22-LR-6X ${ }^{92}$ and HA22-LR-8M ${ }^{93}$ were then constructed by combining the HA22-LR deletion with immunogenic epitope removal. Both have a further reduced immunogenicity while retaining a high antitumor activity at high doses. ${ }^{94}$ Based on this knowledge, Stish et al linked human epidermal growth factor (EGF) and IL-4 to the B cell epitope-deleted PE38 to create a bispecific immunotoxintargeting mesothelioma. When administrated to a mouse model, the immunogenicity was greatly reduced with no apparent compromises in antitumor activity. ${ }^{95}$ Many more of mutants were constructed by Pastan's laboratory for the purpose of reducing immunogenicity. ${ }^{56,87,91}$ Human-derived cytotoxic proteins such as GrB or RNase were used to construct immunotoxin to further eliminate the immunogenicity. Engineering a targeting portion to increase the affinity could therefore reduce the nonspecific toxicity. By introducing three amino acid mutations in CDR3 of the heavy chain of the Fv, moxetumomab pasudotox (Lumoxiti) showed a 14fold increase in affinity and a 50-fold increase in antitumor activity against HCL and CLL cells. ${ }^{2}$ As mentioned above, a bispecific antibody can increase specificity by simultaneously binding different targets. Combining this advantage, researchers can further decrease immunotoxin nonspecific toxicity by employing dual targeting moieties. ${ }^{96-98}$ Using the deimmunizing strategy and dual targeting strategy, Vallera et $\mathrm{al}^{99}$ developed 2219KDEL7mut, a PE38-derived immunotoxin simultaneously targeting CD19 and CD22 with improved cytotoxic activity.

Although newer versions of immunotoxins are constructed with improved safety and exhibit sound potency in treating various cancers, the dose administrated to achieve efficient therapeutic outcomes is limited, mainly due to the immunotoxin-related side effects. Most commonly reported toxicities against normal cells and tissues are vascular leak syndrome (VLS), hepatotoxicity, and renal toxicity. Several studies have been reported and indicated that VLS may be resulted from the weak binding of immunotoxins, especially the RTA-based ones to normal endothelial cells when exiting blood vessels to targeting cells and tissues. ${ }^{100-102}$ Antibody fragments were used to construct immunotoxins to reduce the molecular size and decrease the in vivo half-life thus preventing their prolonged contact with vascular cells. It was reported that RTA would bind directly to endothelial cells, ${ }^{102}$ and a three-amino acid motif was identified to contribute to the toxicity. Then this motif was mutated to generate a new construct which showed less VLS in mice. ${ }^{102}$ VLS caused by truncated PE- and DT-based immunotoxins may rarely be dose-limiting due to the relative short half-lives in plasma. It was reported that PE- and DTbased immunotoxins may bind to the endothelial cells via the interaction between the targeting moiety and endothelial cells. $^{11}$

\section{Production of Immunotoxins}

For the recombinant expression of toxin-based biotherapeutics, a crucial step lies not only in the choice of the production host but also in the accurate design of the fusion proteins. To avoid or limit the toxicity to production host cells without sacrificing a consistent yield, several systems from bacterial to mammalian host cells have been employed. ${ }^{103-106}$ In the early stage, immunotoxins were assembled through chemical conjugation of the toxin molecule with an antibody IgG that could be manufactured in mammalian systems. To avoid complicated manufacturing steps, an $E$. coli host system has been commonly used for expressing antibody fragment-toxin fusion proteins without chemical conjugation. ${ }^{105}$ The fusion proteins were expressed as an inclusion body that can be purified with no toxic activity to the host cells. Due to limitation of protein size, the entire length of IgG would be difficult to be expressed in E. coli compared to a fragment of the IgG. So $\mathrm{ScFv}$, single-domain antibody or other format of small size of the molecules would be logically considered as the targeting partners in the molecular design, which makes it easy to apply the $E$. coli system to produce the immunotoxins.

Immunotoxins could be historically categorized into three generations, and the construction and production strategy were developed to meet each generation. The first-generation immunotoxins were conjugates consisting of a whole toxin to an intact antibody. The antibody portion and the toxin portion were prepared separately and chemically conjugated in vitro to form the final fusion proteins. The linkage may be a disulfide bond or a nonreducible thioether bond. The problem of the first-generation immunotoxins was the nonspecific toxicity to normal cells resulted from the intact toxin to the circulation. In addition, the linkage may not be stable in circulation and would generate unconjugated mAbs which may block the tumor antigen and decrease the antitumor efficacy. The binding domain of the toxin portion was eliminated with the secondgeneration immunotoxins; however, chemical conjugation was still used to link the two parts, which might not be stable in circulation time. With further rational design and optimization, the third-generation immunotoxins could be constructed to form a fusion protein of a fragment of an IgG and a part of toxin with a binding domain. When it comes to the expression of the constructs, E. coli, yeast, and CHO cell systems could be used to meet different needs. Among these, the E. coli expression system is the most widely employed one, although this system could not correctly fold the protein of interest with a complex structure. Basically, the immunotoxins are expressed in E. coli as inclusion bodies, followed by denaturing and refolding and a further purification process to obtain the final product. ${ }^{105} \mathrm{By}$ introducing an ammonium sulfate precipitation, a cGMP purification process for preparing MR1-1 and HA22 afforded high yield and acceptable purity. ${ }^{105}$ An eukaryotic system with resistance to toxin, e.g., DT, may be used to produce immunotoxins. Based on this theory, several groups developed mammalian-cell immunotoxin-expression strategies to produce immunotoxins without serious toxicity to the host cells. ${ }^{107,108}$ The chloroplast of green algae demonstrates the ability to fold and assemble complex eukaryotic 
proteins, ${ }^{109}$ while the machinery of the chloroplast resembles that of a prokaryote, thus it could be used to accumulate eukaryotic toxins. Taking these advantages of algae, Tran et al produced correctly formed immunotoxins with full bioactivities in vivo and in vitro. ${ }^{109-111}$

Due to cytotoxicity by toxins in a variety of cells, immunotoxins with a full length of $\operatorname{IgG}$ were normally not expressed in mammalian cells. Escherichia coli-based production procedures to produce fragments of antibody fused with a toxin were seen in many cases. However, it was recently reported that a DT-resistant cell line enabled a variety of cell lines robust for production of DT-encoding lentivirus. $^{112}$

Besides the above-mentioned construction and production strategies, there are quite a few interesting designs of immunotoxin molecules, or new ways to link the toxin with the targeting moiety. Lee et al constructed an immunotoxin via site-specific conjugation of anti-Her2 IgG with PE24.83. The two proteins were conjugated using a bifunctional linker having dibenzocyclooctyne and maleimide groups. The trastuzumab-PE24 conjugate was cytotoxic to Her2-overexpressing cell lines. ${ }^{76}$ Researchers utilized split inteins to generate immunotoxins against HER $1 / 2,{ }^{113}$ while Wang et al reported reduction of nonspecific toxicity of immunotoxin by intein-mediated reconstitution on target cells. ${ }^{5}$ Nanobody-based immunotoxins on several targets including CD7, CD38, and VEGFR2 were constructed and tumor-inhibitory effects were evaluated. ${ }^{114-116}$

\section{Conclusions}

Immunotoxins are chimeric proteins that combine the advantages of the specificity of the targeting portion and the potent cytotoxicity of protein toxins. And the area of immunotoxin development is in rapid expansion. To date, two immunotoxins, Ontak and anti-CD22 with PE38, have been approved by the U.S. FDA to treat CTCL and HCL. And clinical trials of other immunotoxins have been performed in hematologic malignancies and solid tumors. Immunotoxins could be used as a single agent or in combination with other agents. At present, the truncated forms of bacterial-derived protein toxin PE and DT are the most frequently used toxins for immunotoxin development. These foreign-protein-related immunogenicity will affect the therapeutic outcome by inducing the formation of neutralizing antibodies, especially in solid tumor treatment. Thus future research efforts will lie on further reducing the immunogenicity or humanizing the toxic moiety or even utilizing full human-origin protein cytotoxins to construct immunotoxins. Further, identifying novel cancer-related antigens or receptors with high specificity and selectivity and $\mathrm{mAbs}$ ready to be internalized once bound to the targets is another aspect that should be extensively worked on. Efforts also should be devoted to optimize the constructs' orientation and MW and the linkage strategies to reduce the nonspecific toxicity to normal tissues and achieve a higher max tolerance dosage to enhance the therapeutic outcome. Coadministration with other agents such as chemotherapies and immunosuppressors should also be considered to augment the therapeutic outcomes either by increasing cytotoxic activity or reducing immunogenicity. Immunotoxin manufacturing is another issue that should be addressed. A mammalian cell expression system has the capability to produce $\mathrm{mAb}$ and its fragments, but it is susceptible to toxins. It can be utilized to produce soluble immunotoxins in a correct form if a split intein mediated protein ligation strategy was introduced. With further improvements, it is envisaged that in the near future immunotoxins will expand the repertoire for treating cancers.

Conflicts of Interest

The authors declare no conflict of interest.

\section{References}

1 Köhler G, Milstein C. Continuous cultures of fused cells secreting antibody of predefined specificity. Nature 1975;256(5517): 495-497

2 Pento JT. Monoclonal antibodies for the treatment of cancer. Anticancer Res 2017;37(11):5935-5939

3 Opaliński Ł, Szymczyk J, Szczepara M, et al. High affinity promotes internalization of engineered antibodies targeting FGFR1. Int J Mol Sci 2018;19(05):E1435

4 Donaghy $\mathrm{H}$. Effects of antibody, drug and linker on the preclinical and clinical toxicities of antibody-drug conjugates. MAbs 2016;8 (04):659-671

5 Wang J, Han L, Chen J, Xie Y, Jiang H, Zhu J. Reduction of nonspecific toxicity of immunotoxin by intein mediated reconstitution on target cells. Int Immunopharmacol 2019;66:288-295

6 Leshem Y, Pastan I. Pseudomonas exotoxin immunotoxins and antitumor immunity: from observations at the patient's bedside to evaluation in preclinical models. Toxins (Basel) 2019;11(01):E20

7 Han L, Chen J, Ding K, et al. Efficient generation of bispecific IgG antibodies by split intein mediated protein trans-splicing system. Sci Rep 2017;7(01):8360

8 Trabolsi A, Arumov A, Schatz JH. T cell-activating bispecific antibodies in cancer therapy. J Immunol 2019;203(03):585-592

9 Russell L, Peng KW, Russell SJ, Diaz RMOncolytic viruses: BioDrugs 20190ct;33(05):485-501

10 Mazor R, Onda M, Pastan I. Immunogenicity of therapeutic recombinant immunotoxins. Immunol Rev 2016;270(01):152-164

11 Vallera DA, Kreitman RJ. Immunotoxins targeting B cell malignancy-progress and problems with immunogenicity. Biomedicines 2018;7(01):E1

12 Nobre CF, Newman MJ, DeLisa A, Newman P. Moxetumomab pasudotox-tdfk for relapsed/refractory hairy cell leukemia: a review of clinical considerations. Cancer Chemother Pharmacol 2019;84(02):255-263

13 Madhumathi J, Verma RS. Therapeutic targets and recent advances in protein immunotoxins. Curr Opin Microbiol 2012;15(03): 300-309

14 Alewine C, Hassan R, Pastan I. Advances in anticancer immunotoxin therapy. Oncologist 2015;20(02):176-185

15 Akbari B, Farajnia S, Ahdi Khosroshahi S, et al. Immunotoxins in cancer therapy: review and update. Int Rev Immunol 2017;36 (04):207-219

16 Madhumathi J, Devilakshmi S, Sridevi S, Verma RS. Immunotoxin therapy for hematologic malignancies: where are we heading? Drug Discov Today 2016;21(02):325-332

17 Spiess K, Jakobsen MH, Kledal TN, Rosenkilde MM. The future of antiviral immunotoxins. J Leukoc Biol 2016;99(06):911-925

18 Bourgeois M, Bailly C, Frindel M, et al. Radioimmunoconjugates for treating cancer: recent advances and current opportunities. Expert Opin Biol Ther 2017;17(07):813-819

19 Sahota S, Vahdat LT. Sacituzumab govitecan: an antibody-drug conjugate. Expert Opin Biol Ther 2017;17(08):1027-1031 
20 Lambert JM, Morris CQ. Antibody-drug conjugates(ADCs) for personalized treatment of solid tumors: a review. Adv Ther 2017;34(05):1015-1035

21 Sassoon I, Blanc V. Antibody-drug conjugate (ADC) clinical pipeline: a review. Methods Mol Biol 2013;1045:1-27

22 Minich SS. Brentuximab vedotin: a new age in the treatment of Hodgkin lymphoma and anaplastic large cell lymphoma. Ann Pharmacother 2012;46(03):377-383

23 Arannilewa AJ, Suleiman Alakanse O, Adesola AO, et al. Molecular docking analysis of Cianidanol fromGinkgo biloba with HER2+ breast cancer target. Bioinformation 2018;14(09):482-487

24 Mullard A. Maturing antibody-drug conjugate pipeline hits 30. Nat Rev Drug Discov 2013;12(05):329-332

25 Aghevlian S, Boyle AJ, Reilly RM. Radioimmunotherapy of cancer with high linear energy transfer (LET) radiation delivered by radionuclides emitting $\alpha$-particles or Auger electrons. Adv Drug Deliv Rev 2017;109:102-118

26 Steiner M, Neri D. Antibody-radionuclide conjugates for cancer therapy: historical considerations and new trends. Clin Cancer Res 2011;17(20):6406-6416

27 Manoukian G, Hagemeister F. Denileukin diftitox: a novel immunotoxin. Expert Opin Biol Ther 2009;9(11):1445-1451

28 Wayne AS, Shah NN, Bhojwani D, et al. Phase 1 study of the antiCD22 immunotoxin moxetumomab pasudotox for childhood acute lymphoblastic leukemia. Blood 2017;130(14):1620-1627

29 Kreitman RJ. Hairy cell leukemia: present and future directions. Leuk Lymphoma 2019;60(12):2869-2879

30 Wang $\mathrm{H}$, Song S, Kou G, et al. Treatment of hepatocellular carcinoma in a mouse xenograft model with an immunotoxin which is engineered to eliminate vascular leak syndrome. Cancer Immunol Immunother 2007;56(11):1775-1783

31 Wayne AS, Fitzgerald DJ, Kreitman RJ, Pastan I. Immunotoxins for leukemia. Blood 2014;123(16):2470-2477

32 Huang NY, Zhou XK, Qiu J, et al. Synergistic cytotoxic effect of anti-EGFR/gelonin immunotoxin combined with taxol a antitumor effects and its mechanism. World J Cancer Res 2014;4:4-9

33 Hlongwane P, Mungra N, Madheswaran S, Akinrinmade OA, Chetty S, Barth S. Human granzyme B based targeted cytolytic fusion proteins. Biomedicines 2018;6(02):E72

34 Kurschus FC, Fellows E, Stegmann E, Jenne DE. Granzyme B delivery via perforin is restricted by size, but not by heparan sulfate-dependent endocytosis. Proc Natl Acad Sci U S A 2008; 105(37):13799-13804

35 Besenicar MP, Metkar S, Wang B, Froelich CJ, Anderluh G. Granzyme B translocates across the lipid membrane only in the presence of lytic agents. Biochem Biophys Res Commun 2008;371(03):391-394

36 Bots M, Medema JP. Granzymes at a glance. J Cell Sci 2006;119(Pt 24):5011-5014

37 Mangan MS, Melo-Silva CR, Luu J, et al. A pro-survival role for the intracellular granzyme B inhibitor Serpinb9 in natural killer cells during poxvirus infection. Immunol Cell Biol 2017;95(10): 884-894

38 Ardelt W, Ardelt B, Darzynkiewicz Z. Ribonucleases as potential modalities in anticancer therapy. Eur J Pharmacol 2009;625(13):181-189

39 De Lorenzo C, D’Alessio G. From immunotoxins to immunoRNases. Curr Pharm Biotechnol 2008;9(03):210-214

40 Rybak SM, Arndt MA, Schirrmann T, Dübel S, Krauss J. Ribonucleases and immunoRNases as anticancer drugs. Curr Pharm Des 2009;15(23):2665-2675

41 Kreitman RJ, Tallman MS, Robak T, et al. Phase I trial of anti-CD22 recombinant immunotoxin moxetumomab pasudotox (CAT8015 or HA22) in patients with hairy cell leukemia. J Clin Oncol 2012;30(15):1822-1828

42 Entwistle J, Kowalski M, Brown J, et al. The preclinical and clinical evaluation of VB4-845: an immunotoxin with a de-immunized payload for the systemic treatment of solid tumors. In: Phillips
GL, ed. Antibody-Drug Conjugates and Immunotoxins: from Preclinical Development to Therapeutic Applications. New York, NY: Springer; 2013:349-367

43 Lai EW, Joshi BH, Martiniova L, et al. Overexpression of interleukin-13 receptor-alpha2 in neuroendocrine malignant pheochromocytoma: a novel target for receptor directed anti-cancer therapy. J Clin Endocrinol Metab 2009;94(08):2952-2957

44 Kreitman RJ, Hassan R, Fitzgerald DJ, Pastan I. Phase I trial of continuous infusion anti-mesothelin recombinant immunotoxin SS1P. Clin Cancer Res 2009;15(16):5274-5279

45 Ochiai H, Archer GE, Herndon JE II, et al. EGFRvIII-targeted immunotoxin induces antitumor immunity that is inhibited in the absence of CD4 + and CD8 + T cells. Cancer Immunol Immunother 2008;57(01):115-121

46 Li YM, Hall WA. Targeted toxins in brain tumor therapy. Toxins (Basel) 2010;2(11):2645-2662

47 Mahmud H, Dälken B, Wels WS. Induction of programmed cell death in ErbB2/HER2-expressing cancer cells by targeted delivery of apoptosis-inducing factor. Mol Cancer Ther 2009;8(06): 1526-1535

48 Ding D. RE: Long-term safety of combined intracerebral delivery of free gadolinium and targeted chemotherapeutic agent PRX321 printing error. Neurol Res 2011;33(04):448

49 Hassan R, Thomas A, Alewine C, Le DT, Jaffee EM, Pastan I. Mesothelin immunotherapy for cancer: Ready for prime time. J Clin Oncol 2016;34(34):4171-4179

50 Liu TF, Hall PD, Cohen KA, et al. Interstitial diphtheria toxinepidermal growth factor fusion protein therapy produces regressions of subcutaneous human glioblastoma multiforme tumors in athymic nude mice. Clin Cancer Res 2005;11(01):329-334

51 Weaver M, Laske DW. Transferrin receptor ligand-targeted toxin conjugate (Tf-CRM107) for therapy of malignant gliomas. J Neurooncol 2003;65(01):3-13

52 Mueller BU, Seipel K, Pabst T. Myelodysplastic syndromes and acute myeloid leukemias in the elderly. Eur J Intern Med 2018; 58:28-32

53 Short NJ, Rytting ME, Cortes JE. Acute myeloid leukaemia. Lancet 2018;392(10147):593-606

54 Malek TR, Castro I. Interleukin-2 receptor signaling: at the interface between tolerance and immunity. Immunity 2010;33 (02):153-165

55 Powell DJ Jr, Felipe-Silva A, Merino MJ, et al. Administration of a CD25-directed immunotoxin, LMB-2, to patients with metastatic melanoma induces a selective partial reduction in regulatory $\mathrm{T}$ cells in vivo. J Immunol 2007;179(07):4919-4928

56 Kaplan G, Mazor R, Lee F, Jang Y, Leshem Y, Pastan I. Improving the in vivo efficacy of an anti-Tac (CD25) immunotoxin by Pseudomonas exotoxin A domain II engineering. Mol Cancer Ther 2018;17(07):1486-1493

57 Shimamura T, Husain SR, Puri RK. The IL-4 and IL-13 pseudomonas exotoxins: new hope for brain tumor therapy. Neurosurg Focus 2006;20(04):E11

58 Sokolova E, Guryev E, Yudintsev A, Vodeneev V, Deyev S, Balalaeva I. HER2-specific recombinant immunotoxin 4D5scFv-PE40 passes through retrograde trafficking route and forces cells to enter apoptosis. Oncotarget 2017;8(13):22048-22058

59 Rainov NG, Söling A. Clinical studies with targeted toxins in malignant glioma. Rev Recent Clin Trials 2006;1(02):119-131

60 MacDonald GC, Rasamoelisolo M, Entwistle J, et al. A phase I clinical study of VB4-845: weekly intratumoral administration of an anti-EPCAM recombinant fusion protein in patients with squamous cell carcinoma of the head and neck. Drug Des Devel Ther 2009;2:105-114

61 Hassan R, Ho M. Mesothelin targeted cancer immunotherapy. Eur J Cancer 2008;44(01):46-53

62 Hosseinian SA, Haddad-Mashadrizeh A, Dolatabadi S. Simulation and stability assessment of anti-EpCAM immunotoxin for cancer therapy. Adv Pharm Bull 2018;8(03):447-455 
63 Lv M, Qiu F, Li T, et al. Construction, expression, and characterization of a recombinant immunotoxin targeting EpCAM. Mediators Inflamm 2015;2015:460264

64 Vallera DA, Chen H, Sicheneder AR, Panoskaltsis-Mortari A, Taras EP. Genetic alteration of a bispecific ligand-directed toxin targeting human CD19 and CD22 receptors resulting in improved efficacy against systemic B cell malignancy. Leuk Res 2009;33 (09):1233-1242

65 Du X, Beers R, Fitzgerald DJ, Pastan I. Differential cellular internalization of anti-CD19 and -CD22 immunotoxins results in different cytotoxic activity. Cancer Res 2008;68(15): 6300-6305

66 Robak T. Hairy-cell leukemia variant: recent view on diagnosis, biology and treatment. Cancer Treat Rev 2011;37(01):3-10

67 Kreitman RJ, Pastan I. Antibody fusion proteins: anti-CD22 recombinant immunotoxin moxetumomab pasudotox. Clin Cancer Res 2011;17(20):6398-6405

68 Pui $\mathrm{CH}$, Campana D, Pei D, et al. Treating childhood acute lymphoblastic leukemia without cranial irradiation. N Engl J Med 2009;360(26):2730-2741

69 Doronina SO, Bovee TD, Meyer DW, et al. Novel peptide linkers for highly potent antibody-auristatin conjugate. Bioconjug Chem 2008;19(10):1960-1963

70 Younes A, Bartlett NL, Leonard JP, et al. Brentuximab vedotin (SGN-35) for relapsed CD30-positive lymphomas. N Engl J Med 2010;363(19):1812-1821

71 Borthakur G, Rosenblum MG, Talpaz M, et al. Phase 1 study of an anti-CD33 immunotoxin, humanized monoclonal antibody M195 conjugated to recombinant gelonin (HUM-195/rGEL), in patients with advanced myeloid malignancies. Haematologica 2013;98(02):217-221

72 Dean A, Talpaz M, Kantarjian H, et al. Phase I clinical trial of the antiCD33 immunotoxin HuM195/rgel in patients (pts) with advanced myeloid malignancies. J Clin Oncol 2010;28(Suppl 15):6549

73 Li N, Fu H, Hewitt SM, Dimitrov DS, Ho M. Therapeutically targeting glypican-2 via single-domain antibody-based chimeric antigen receptors and immunotoxins in neuroblastoma. Proc Natl Acad Sci U S A 2017;114(32):E6623-E6631

74 Amadori S, Suciu S, Selleslag D, et al. Gemtuzumab ozogamicin versus best supportive care in older patients with newly diagnosed acute myeloid leukemia unsuitable for intensive chemotherapy: results of the randomized phase III EORTC-GIMEMA AML-19 trial. J Clin Oncol 2016;34(09):972-979

75 Yamaizumi M, Mekada E, Uchida T, Okada Y. One molecule of diphtheria toxin fragment $A$ introduced into a cell can kill the cell. Cell 1978;15(01):245-250

76 Lee BS, Lee Y, Park J, et al. Construction of an immunotoxin via site-specific conjugation of anti-Her2 IgG and engineered Pseudomonas exotoxin A. J Biol Eng 2019;13:56

77 Zhao P, Wang P, Dong S, et al. Depletion of PD-1-positive cells ameliorates autoimmune disease. Nat Biomed Eng 2019;3(04): 292-305

78 Jiao P, Zhang J, Dong Y, Wei D, Ren Y. Construction and characterization of the recombinant immunotoxin RTA-4D5-KDEL targeting HER2/neu-positive cancer cells and locating the endoplasmic reticulum. Appl Microbiol Biotechnol 2018;102(22): 9585-9594

79 Weldon JE, Pastan I. A guide to taming a toxin-recombinant immunotoxins constructed from Pseudomonas exotoxin A for the treatment of cancer. FEBS J 2011;278(23):4683-4700

80 Udaondo Z, Ramos JL, Segura A, Krell T, Daddaoua A. Regulation of carbohydrate degradation pathways in Pseudomonas involves a versatile set of transcriptional regulators. Microb Biotechnol 2018;11(03):442-454

81 Murphy JR. Mechanism of diphtheria toxin catalytic domain delivery to the eukaryotic cell cytosol and the cellular factors that directly participate in the process. Toxins (Basel) 2011;3 (03):294-308
82 Michalska M, Wolf P. Pseudomonas exotoxin A: optimized by evolution for effective killing. Front Microbiol 2015;6:963

83 Parveen S, Bishai W, Murphy J. Corynebacterium diphtheriae: Diphtheria Toxin, the tox Operon, and Its Regulation by $\mathrm{Fe}^{+}$ Activation of apo-DtxR. Microbiol Spectrum7(04):GPP3-00632019. doi:10.1128/microbiolspec.GPP3-0063-2019

84 Rust A, Partridge LJ, Davletov B, Hautbergue GM. The use of plantderived ribosome inactivating proteins in immunotoxin development: past, present and future generations. Toxins (Basel) 2017;9(11):E344

85 Polito L, Bortolotti M, Battelli MG, Calafato G, Bolognesi A. Ricin: an ancient story for a timeless plant toxin. Toxins (Basel)2019;11 (06):E324

86 Cremer C, Hehmann-Titt G, Schiffer S, et al. Engineered versions of granzyme B and angiogenin overcome intrinsic resistance to apoptosis mediated by human cytolytic fusion proteins. In: Verma RS, ed. Resistance to Immunotoxins in Cancer Therapy. Cham: Springer International Publishing; 2015:185-219

87 Mazor R, Eberle JA, Hu X, et al. Recombinant immunotoxin for cancer treatment with low immunogenicity by identification and silencing of human T-cell epitopes. Proc Natl Acad Sci U S A 2014;111(23):8571-8576

88 Onda M, Vincent JJ, Lee B, Pastan I. Mutants of immunotoxin anti$\mathrm{Tac}(\mathrm{dsFv})-\mathrm{PE} 38$ with variable number of lysine residues as candidates for site-specific chemical modification. 1. Properties of mutant molecules. Bioconjug Chem 2003;14(02):480-487

89 Kollmorgen G, Palme K, Seidl A, et al. A re-engineered immunotoxin shows promising preclinical activity in ovarian cancer. Sci Rep 2017;7(01):18086

90 Onda M, Nagata S, FitzGerald DJ, et al. Characterization of the B cell epitopes associated with a truncated form of Pseudomonas exotoxin (PE38) used to make immunotoxins for the treatment of cancer patients. J Immunol 2006;177(12):8822-8834

91 Onda M, Beers R, Xiang L, Nagata S, Wang QC, Pastan I. An immunotoxin with greatly reduced immunogenicity by identification and removal of B cell epitopes. Proc Natl Acad Sci U S A 2008;105(32):11311-11316

92 Weldon JE, Xiang L, Chertov O, et al. A protease-resistant immunotoxin against CD22 with greatly increased activity against CLL and diminished animal toxicity. Blood 2009;113 (16):3792-3800

93 Hansen JK, Weldon JE, Xiang L, Beers R, Onda M, Pastan I. A recombinant immunotoxin targeting CD22 with low immunogenicity, low nonspecific toxicity, and high antitumor activity in mice. J Immunother 2010;33(03):297-304

94 Onda M, Beers R, Xiang L, et al. Recombinant immunotoxin against B-cell malignancies with no immunogenicity in mice by removal of B-cell epitopes. Proc Natl Acad Sci U S A 2011;108 (14):5742-5747

95 Stish BJ, Oh S, Chen H, Dudek AZ, Kratzke RA, Vallera DA. Design and modification of EGF4KDEL 7Mut, a novel bispecific liganddirected toxin, with decreased immunogenicity and potent antimesothelioma activity. Br J Cancer 2009;101(07):1114-1123

96 Liu W, Onda M, Lee B, et al. Recombinant immunotoxin engineered for low immunogenicity and antigenicity by identifying and silencing human B-cell epitopes. Proc Natl Acad Sci U S A 2012;109(29):11782-11787

97 Izidoro MA, Gouvea IE, Santos JA, et al. A study of human furin specificity using synthetic peptides derived from natural substrates, and effects of potassium ions. Arch Biochem Biophys 2009;487(02):105-114

98 Frankel AE, Woo JH. Bispecific immunotoxins. Leuk Res 2009;33 (09):1173-1174

99 Vallera DA, Oh S, Chen H, Shu Y, Frankel AE. Bioengineering a unique deimmunized bispecific targeted toxin that simultaneously recognizes human $\mathrm{CD} 22$ and $\mathrm{CD} 19$ receptors in a mouse model of B-cell metastases. Mol Cancer Ther 2010;9(06): 1872-1883 
100 Bokori-Brown M, Metz J, Petrov PG, et al. Interactions between Pseudomonas immunotoxins and the plasma membrane: Implications for CAT-8015 immunotoxin therapy. Front Oncol 2018; $8: 553$

101 Liu XY, Pop LM, Schindler J, Vitetta ES. Immunotoxins constructed with chimeric, short-lived anti-CD22 monoclonal antibodies induce less vascular leak without loss of cytotoxicity. MAbs 2012;4(01):57-68

102 Moss DL, Park HW, Mettu RR, Landry SJ. Deimmunizing substitutions in Pseudomonas exotoxin domain III perturb antigen processing without eliminating T-cell epitopes. J Biol Chem 2019;294(12):4667-4681

103 Zuppone S, Fabbrini MS, Vago R. Hosts for hostile protein production: the challenge of recombinant immunotoxin expression. Biomedicines 2019;7(02):E38

104 Jiang H, Cai J, Zhu J. Biotechnological Pharmaceutics. 1st ed. Beijing: Science Publisher; 2017

105 Jiang H, Xie Y, Burnette A, et al. Purification of clinical-grade disulfide stabilized antibody fragment variable-Pseudomonas exotoxin conjugate (dsFv-PE38) expressed in Escherichia coli. Appl Microbiol Biotechnol 2013;97(02):621-632

106 Zhu J. Mammalian cell protein expression for biopharmaceutical production. Biotechnol Adv 2012;30(05):1158-1170

$107 \mathrm{Hu} \mathrm{Y,} \mathrm{Zhang} \mathrm{L,} \mathrm{Wu} \mathrm{R,} \mathrm{et} \mathrm{al.} \mathrm{Specific} \mathrm{killing} \mathrm{of} \mathrm{CCR9} \mathrm{high-}$ expressing acute $\mathrm{T}$ lymphocytic leukemia cells by CCL25 fused with PE38 toxin. Leuk Res 2011;35(09):1254-1260

108 Suwanpatcharakul M, Pakdeecharoen C, Visuttitewin S, Pesirikan N, Chauvatcharin S, Pongtharangkul T. Process optimization for an industrial-scale production of Diphtheria toxin by Corynebacterium diphtheriae PW8. Biologicals 2016;44(06): 534-539

109 Tran M, Van C, Barrera DJ, et al. Production of unique immunotoxin cancer therapeutics in algal chloroplasts. Proc Natl Acad Sci U S A 2013;110(01):E15-E22

110 Rasala BA, Mayfield SP. The microalga Chlamydomonas reinhardtii as a platform for the production of human protein therapeutics. Bioeng Bugs 2011;2(01):50-54
111 Tran M, Henry RE, Siefker D, et al. Production of anti-cancer immunotoxins in algae: ribosome inactivating proteins as fusion partners. Biotechnol Bioeng 2013;110(11):2826-2835

112 Lange MJ, Lyddon TD, Johnson MC. Diphtheria toxin A-resistant cell lines enable robust production and evaluation of DTAencoding lentiviruses. Sci Rep 2019;9(01):8985

113 Pirzer T, Becher KS, Rieker M, Meckel T, Mootz HD, Kolmar H. Generation of potent anti-HER1/2 immunotoxins by protein ligation using split inteins. ACS Chem Biol 2018;13(08):2058-2066

114 Yu Y, Li J, Zhu X, et al. Humanized CD7 nanobody-based immunotoxins exhibit promising anti-T-cell acute lymphoblastic leukemia potential. Int J Nanomedicine 2017;12:1969-1983

115 Li T, Qi S, Unger M, et al. Immuno-targeting the multifunctional CD38 using nanobody. Sci Rep 2016;6:27055

116 Behdani M, Zeinali S, Karimipour M, et al. Development of VEGFR2-specific nanobody Pseudomonas exotoxin A conjugated to provide efficient inhibition of tumor cell growth. N Biotechnol 2013;30(02):205-209

117 Hall PD, Sinha D, Frankel AE. Fresh frozen plasma and platelet concentrates may increase plasma anti-diphtheria toxin $\operatorname{IgG}$ concentrations: Implications for diphtheria fusion protein therapy. Cancer Immunol Immunother 2006;55(08):928-932

118 Woo JH, Lee YJ, Neville DM, Frankel AE. Pharmacology of antiCD3 diphtheria immunotoxin in CD3 positive T-cell lymphoma trials. Methods Mol Biol 2010;651:157-175

119 Barta SK, Zou Y, Schindler J, et al. Synergy of sequential administration of a deglycosylated ricin A chain-containing combined anti-CD19 and anti-CD22 immunotoxin (Combotox) and cytarabine in a murine model of advanced acute lymphoblastic leukemia. Leuk Lymphoma 2012;53(10):1999-2003

120 Schnell R, Staak O, Borchmann P, et al. A phase I study with an anti-CD30 ricin A-chain immunotoxin (Ki-4.dgA) in patients with refractory CD30+ Hodgkin's and non-Hodgkin's lymphoma. Clin Cancer Res 2002;8(06):1779-1786

121 Zhu S, Liu Y, Wang PC, Gu X, Shan L. Recombinant immunotoxin therapy of glioblastoma: smart design, key findings, and specific challenges. BioMed Res Int 2017;2017:7929286 